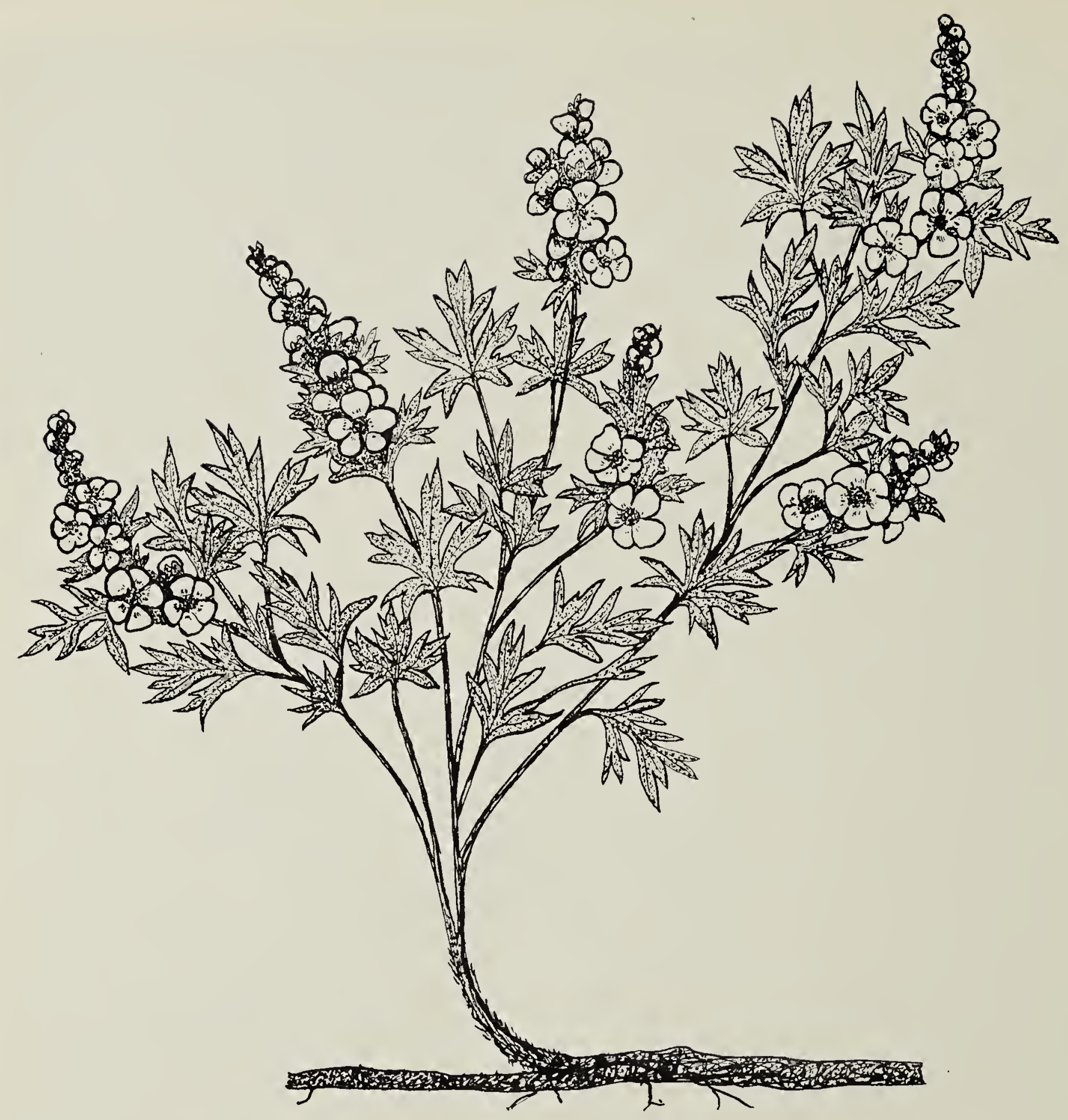

Drawing by K. F. Best

\section{SCARLET MALLOW - A NATIVE DRYLANDER}

by Keith F. Best, Swift Current

Scarlet Mallow (Sphaeracea coccinea (Pursh) Rydb.) is a native perennial growing up to a foot in height from a woody base with deep penetrating roots that protect it from drought. Known also as Red False Mallow, or Globe-mallow, this species derives its scientific name from the Greek sphaira, a sphere, and alcea, a mallow, from its spherically-shaped fruit. (Some authorities use Malvastrum coccineum (Pursh) A. Gray).

The leaves are deeply three-cleft, and the lateral divisions are again deeply cleft. Fine white, star-shaped hairs cover the leaves giving the plant a somewhat grayish appearance.

In late June and early July, it produces dense, short, raceme-like inflorescences bearing brick red or tomatocolored flowers, a shade rarely found in prairie flowers.

Scarlet Mallow is found throughout the dry prairie on lighter soils of our southern areas. Although common on virgin prairie, it is not generally noticed there, nor does it form large clumps. On disturbed soil or roadside grades however, it often takes full possession of large areas and blossoms freely. 